\title{
Erratum to: Likelihood based approaches to handling data below the quantification limit using NONMEM VI
}

\author{
Jae Eun Ahn • Mats O. Karlsson • Adrian Dunne • \\ Thomas M. Ludden
}

Published online: 4 June 2010

(C) Springer Science+Business Media, LLC 2010

\section{Erratum to: J Pharmacokinet Pharmacodyn (2008) 35(4):401-421 10.1007/s10928-008-9094-4}

The following list of corrections applies to the article, "Likelihood based approaches to handling data below the quantification limit using NONMEM VI" by Jae Eun Ahn, Mats O. Karlsson, Adrian Dunne, Thomas M. Ludden. The article appeared in the Journal of Pharmacokinetics and Pharmacodynamics, Volume 35, Number 4, August 2008, pp. 401-421.

Page 402:

- Method 7 (M7): Replace all BQL observations with 0 and apply extended least squares estimation.

Page 419, Appendix Part I.b, M3 Code:

$\mathrm{DUM}=(\mathrm{LOQ}-\mathrm{IPRED}) /\left(\mathrm{SIG}^{*} \mathrm{IPRED}\right)$

The online version of the original article can be found under doi:10.1007/s10928-008-9094-4.

J. E. Ahn $(\bowtie) \cdot$ T. M. Ludden

Pharmacometrics R \& D, ICON Development Solutions, Ellicott City, MD, USA

e-mail: jaeeun.ahn@pfizer.com

M. O. Karlsson

Department of Pharmaceutical Biosciences, Uppsala University, Uppsala, Sweden

\section{A. Dunne}

School of Mathematical Sciences, University of College Dublin, Belfield, Dublin 4, Ireland

Present Address:

J. E. Ahn

Global Pharmacometrics, Pfizer Global Research and Development, New London, CT, USA 
Page 419, Appendix Part I.b, M4 Code:

$\mathrm{DUM}=(\mathrm{LOQ}-\mathrm{IPRED}) /\left(\mathrm{SIG}^{*} \mathrm{IPRED}\right)$

DUM0 $=(0-$ IPRED $) /($ SIG*IPRED $)$

Page 419, Appendix Part I.b, \$ERROR:

Adding "CALLFL=0" or "(ONLY OBSERVATIONS)" is necessary to prevent division by zero for dosing records.

In Part I, the negatively biased estimates for RUV with all data, M1, and M2 were due to the fact that an incorrect true value $(0.025)$ was used in calculating estimation error. The value should have been 0.0225 . The corrected values for RUV assessment are provided in Table 4-7c.

Estimation in Part I.b was redone with the correct code above but using a different Fortran compiler, g77. Simulated data are the same. The new results are provided in Tables $8 \mathrm{c}-10 \mathrm{c}$. M2 tended to be less stable than M3 or M4 at high LOQ values (Table 8c) but still gave less biased estimates than M1. M1 was also fitted to the untransformed data but its estimates were still severely biased as in Part I.a and the results are not presented. M3 and M4 gave very similar and the least biased estimates (Table 9c). Overall precision seems comparable (Table 10c).

Table 4-7c Part I.a: Corrections to Mean Estimation Error (MEE, \%) and Root Mean Squared Estimation Error (RMSE, \%) of RUV

\begin{tabular}{|c|c|c|c|c|c|c|c|c|c|c|c|c|c|c|}
\hline \multirow[t]{2}{*}{ Tables } & \multirow{2}{*}{$\begin{array}{l}\text { LOQ } \\
\text { Methods }\end{array}$} & \multirow{2}{*}{$\begin{array}{l}0 \\
\text { All } \\
\text { data }\end{array}$} & \multicolumn{3}{|l|}{0.2} & \multicolumn{3}{|l|}{0.25} & \multicolumn{3}{|l|}{0.3} & \multicolumn{3}{|l|}{0.4} \\
\hline & & & M1 & M2 & M3 & M1 & M2 & M3 & M1 & M2 & M3 & M1 & M2 & M3 \\
\hline 4 & MEE & 6.43 & -1.83 & 3.69 & 4.29 & -3.67 & 3.86 & 3.25 & -4.15 & 4.59 & 2.78 & -3.68 & 5.43 & 3.39 \\
\hline 5 & RMSE & 7.36 & 4.30 & 5.76 & 5.73 & 5.34 & 5.71 & 5.07 & 5.87 & 6.59 & 5.14 & 5.93 & 7.60 & 6.01 \\
\hline 6 & MEE & 6.21 & -0.191 & 5.52 & 4.49 & -2.00 & 5.96 & 3.25 & -0.716 & 7.67 & 5.05 & 2.39 & 8.68 & 4.22 \\
\hline 7 & RMSE & 7.99 & 5.59 & 8.37 & 7.24 & 6.24 & 9.11 & 5.07 & 6.32 & 10.9 & 8.33 & 8.31 & 12.4 & 8.89 \\
\hline
\end{tabular}

Corrected values in bold

Table 8c Part I.b: The Proportion of BQL Data and the Success Rate (\%) (Extensive Design: 24 samples/individual; untransformed data)

\begin{tabular}{llllll}
\hline & & \multicolumn{3}{l}{ Success Rate $(\%)$} \\
\cline { 5 - 6 } LOQ & BQL Proportion (\%) & All data & M2 (YLO) & M3 (F_FLAG) & M4 (F_FLAG) \\
\hline 0 & 0.00 & 86 & & & \\
0.2 & 12.9 & & 88 & 87 & 88 \\
0.25 & 21.6 & 82 & 85 & 91 \\
0.3 & 29.9 & 81 & 87 & 85 \\
0.4 & 42.9 & 61 & 80 & 78 \\
\hline
\end{tabular}




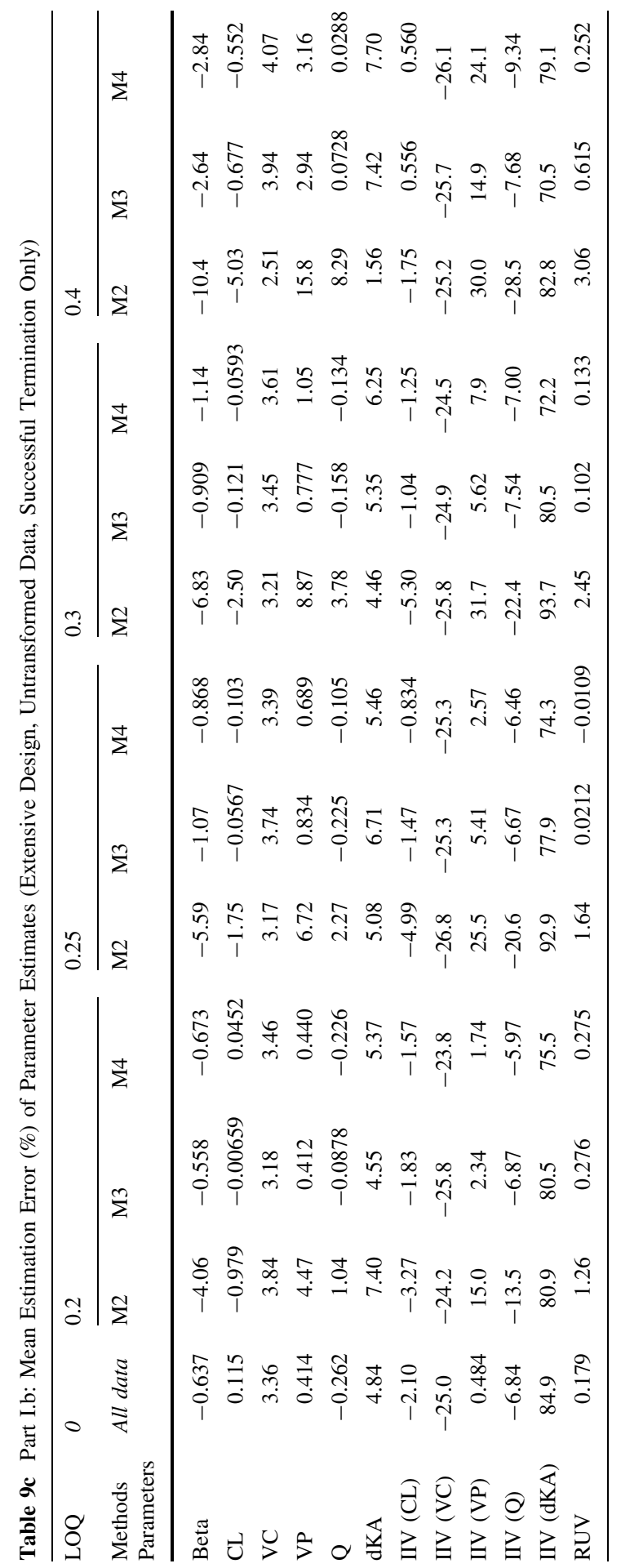




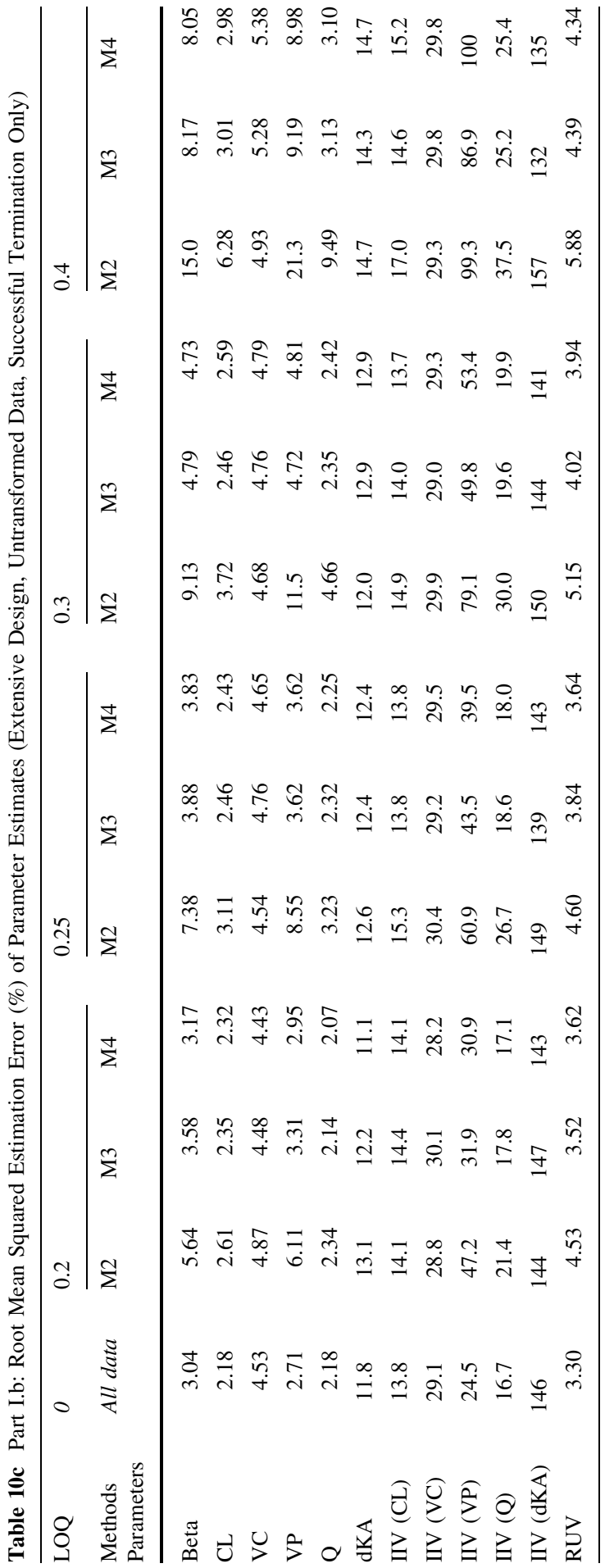

